\title{
artigo
}

Souza, M.G.G.; Gomes, A.M.T.; Santo, F.H.E.; Andrade da Silva, L.; Marta, C.B.; Oliveira, L.A.F.; Mendonça, A.B.;

As práticas religiosas e os mecanismos de superação desenvolvidos por familiares de pacientes no enfrentamento do câncer

\section{As práticas religiosas e os mecanismos de superação desenvolvidos por familiares de pacientes no enfrentamento do câncer}

\author{
Religious practices and surveillance mechanisms developed by patient families in the face of cancer \\ Prácticas religiosas y mecanismos de vigilancia desarrollados por familias pacientes frente al cáncer
}

\section{RESUMO}

Considerando-se o câncer como uma doença que está presente no imaginário das pessoas como sinônimo de morte e sofrimento, geralmente carregada de imagens e conceitos negativos. 0 objetivo do estudo foi conhecer as práticas religiosas como mecanismo de superação desenvolvido por familiares dos pacientes oncológicos. 0 estudo foi orientado pelos pressupostos da Teoria das Representações Sociais. A pesquisa utilizou a abordagem qualitativa e abrangeu 30 familiares de pacientes oncológicos em tratamento quimioterápico de um hospital federal de referência nacional no tratamento do câncer. Os dados foram coletados a partir da realização de entrevistas semiestruturadas e analisados através da análise de conteúdo de Bardin, sistematizada por Oliveira, com o auxílio do software QRS Nvivo 2.0. Através do estudo, apreendemos que as famílias desenvolvem as práticas religiosas como uma forma de superar o sofrimento, o que proporciona coragem e força para vivenciar as adversidades que a doença carrega. DESCRITORES: Câncer; Família; Religiosidade.

\section{ABSTRACT}

Considering cancer as a disease that is present in people's imaginary as a synonym of death and suffering, usually loaded with negative images and concepts. The aim of the study was to know the religious practices as a mechanism of overcoming developed by relatives of cancer patients. The study was guided by the assumptions of the Theory of Social Representations. The research used the qualitative approach and included 30 relatives of cancer patients undergoing chemotherapy at a national referral federal hospital for cancer treatment. Data were collected from semi-structured interviews and analyzed through Bardin content analysis, systematized by Oliveira, with the aid of QRS Nvivo 2.0 software. Through the study, we learn that families develop religious practices to overcome suffering, which provides courage and strength to experience the adversities that the disease carries.

DESCRIPTORS: Cancer; Family; Religiosity.

\section{RESUMEN}

Considerar el cáncer como una enfermedad presente en el imaginario de las personas como sinónimo de muerte y sufrimiento, generalmente cargado de imágenes y conceptos negativos. El objetivo del estudio fue conocer las prácticas religiosas como mecanismo de superación desarrollado por familiares de pacientes con cáncer. El estudio se guió por los supuestos de la Teoría de las representaciones sociales. La investigación utilizó el enfoque cualitativo e incluyó a 30 familiares de pacientes con cáncer sometidos a quimioterapia en un hospital federal de referencia nacional para el tratamiento del cáncer. Los datos se recopilaron de entrevistas semiestructuradas y se analizaron mediante el análisis de contenido de Bardin, sistematizado por Oliveira, con la ayuda del software QRS Nvivo 2.0. A través del estudio, aprendemos que las familias desarrollan prácticas religiosas como una forma de superar el sufrimiento, lo que proporciona coraje y fuerza para experimentar las adversidades que conlleva la enfermedad.

DESCRIPTORES: Gestión de Riesgos; Vigilancia de Guardia; Grupo de Enfermería.

RECEBIDO EM: 04/01/2020 APROVADO EM: 06/01/2020

\section{Maria das Graças Gazel de Souza}

Enfermeira. Doutora em Enfermagem pela Faculdade de Enfermagem da Universidade do Estado do Rio de Janeiro. Rio de Janeiro, Brasil. Enfermeira do Instituto Nacional de Câncer (INCA). ORCID: https//orcid.org/0000-0002-6247-9331

\section{Antonio Marcos Tosoli Gomes}

Enfermeiro. Doutor em Enfermagem pela Escola de Enfermagem Anna Nery da Universidade Federal do Rio de Janeiro. Professor adjunto do Departamento de Enfermagem Médico Cirúrgica e do Programa de Pós-Graduação em Enfermagem da Faculdade de Enfermagem da Universidade do Estado do Rio de Janeiro. ORCID: https//orcid.org/0000-0003-4235-9647 


\section{Fátima Helena do Espírito Santo}

Enfermeira. Professor Adjunto do Departamento de Enfermagem Médico-Cirúrgica e do Programa de Pós-Graduação da Escola de Enfermagem Aurora Afonso Costa de Universidade Federal Fluminense. ORCID: https//orcid.org/0000-0003-4611-5586

\section{Leandro Andrade da Silva}

Enfermeiro. Pós-Doutor em Enfermagem da Universidade do Estado do Rio de Janeiro. Professor da Universidade Veiga de Almeida. ORCID: https//orcid.org/0000-0003-3213-5527

\section{Cristiano Bertolossi Marta}

Enfermeiro. Pós-doutor em Enfermagem pela Escola de Enfermagem Aurora Afonso Costa da Universidade Federal Fluminense (EEAAC/UFF). Professor Adjunto do Departamento de Fundamentos de Enfermagem da Faculdade de Enfermagem da Universidade do Estado do Rio de Janeiro (DFEN/FENF/UERJ). ORCID: https//orcid.org/0000-0002-0635-7970

\section{Luciana Aparecida Faria de Oliveira}

Mestranda em Enfermagem pela Escola de Enfermagem Anna Nery da Universidade Federal do Rio de Janeiro. Rio de Janeiro, Brasil. ORCID: https//orcid.org/0000-0002-6430-1932

\section{Angelo Braga Mendonça}

Mestre em enfermagem pela Escola de Enfermagem Aurora de Afonso Costa. Enfermeiro do Centro de Quimioterapia Adulto do Instituto Nacional de Câncer. ORCID: https//orcid.org/0000-0003-0042-9280

\section{INTRODUÇÃO}

다 ste artigo é resultado de parte da dissertação desenvolvida durante o Curso de Mestrado em Enfermagem da Universidade do Estado do Rio de Janeiro. Considera-se relevante que enfermeiros estejam atentos e sensíveis às necessidades e dimensões espirituais e religiosas que são construídas e vivenciadas pelo paciente com câncer e sua família, uma vez que se acredita que os elementos identificados nesta pesquisa podem subsidiar reflexões e contribuir para a construção de conceitos referentes às vivências da família que sofre ao acompanhar um ente querido com uma doença tão cheia de incertezas, metáforas, construções representacionais e carregada de sofrimento.

Desta maneira, pode-se perceber que os familiares dos pacientes com câncer possuem um modo muito particular de perceber o processo de adoecer por esta entidade mórbida e o de conviver com um familiar doente. Para muitas famílias, o câncer é percebido como um monstro que invade a vida e passa a tomar conta e a dominá-la de tal forma que tira a paz e o sossego, ou seja, o sofrimento envolve tanto o doente, quanto sua família. Além da deterioração emocional que o câncer causa na vida das pessoas, ele ainda é visto como uma doença que destrói também o corpo, ocasionando a perda da saúde física e emocional de todos os envolvidos nesse processo de adoecimento ${ }^{(1)}$.

Nesse sentido, o enfretamento da doença com a ajuda da religiosidade tem se mostrado positivo, uma vez que, contribui para que o doente tenha uma melhora em sua qualidade de vida através da redução do estresse, da ansiedade, aumento de sua adesão ao tratamento proposto e contribuindo no processo de superação da doença.

Atualmente, a palavra enfrentamento vem sendo substituída por Coping. "A língua portuguesa não dispõe de palavra que expresse a complexidade desse termo, porém a sua tradução quer dizer "lidar com", "enfrentar" ou "adaptar-se à". Coping tem sido descrito como a união das estratégias utilizadas pelas pessoas para o enfrentamento de situações que são desconfortáveis como, por exemplo, o estresse ou as doenças.

Dentre as estratégias de Coping, ressalta-se a religiosidade, que pode ter efeito positivo para o paciente, contribuindo para que ocorra uma diminuição das experiências negativas provocadas pelo câncer e ocasionando uma melhora em sua qualidade de vida ${ }^{(3)}$.

A religiosidade pode ser entendida como um conjunto de crenças e práticas pertencentes a uma doutrina, que são compartilhadas e seguidas por um grupo de pessoas através de cultos ou rituais que envolvem necessariamente a noção de fé. Já a espiritualidade se constitui de um sentimento íntimo existencial, uma busca pelo sentido de viver e estar no mundo e que, não necessariamente, estará ligado à crença em algo maior, como um Deus ${ }^{(4)}$.

Realizar educação em saúde para enfermeiros e demais profissionais da área da saúde sobre o tema é importante para que todos estejam preparados, pois, dessa forma, o cuidado oferecido será feito de forma humanizada, assistindo o cliente e seus familiares de forma holística, visto que contemplar as questóes espirituais e religiosas proporcionará momentos de conforto e de paz, transmitindo segurança para o enfrentamento desse momento difícil. Diante do exposto, o objetivo deste estudo foi conhecer as práticas religiosas como mecanismo de superação desenvolvido por familiares dos pacientes oncológicos.

\section{METODOLOGIA}

O presente estudo caracterizou-se por ser uma pesquisa qualitativa descritiva que possui como foco essencial o desejo de conhecer a comunidade, seus traços característicos e seus problemas ${ }^{(5)}$. Além disso, pretende-se descrever, com exatidão, os fatos e os fenômenos de determinada realidade, sem que se pretenda realizar qualquer processo de intervenção na 


\section{artigo}

Souza, M.G.G.; Gomes, A.M.T.; Santo, F.H.E.; Andrade da Silva, L.; Marta, C.B.; Oliveira, L.A.F.; Mendonça, A.B.;

As práticas religiosas e os mecanismos de superação desenvolvidos por familiares de pacientes no enfrentamento do câncer

realidade estudada. $\mathrm{O}$ estudo de natureza qualitativa se preocupa com o universo de valores, crenças, afirmações e significados envolvidos nas relações humanas e que não podem ser quantificadas através de dados numéricos ou de análises estatísticas ${ }^{(6)}$.

No que tange à Teoria das Representações Sociais, optou-se pela abordagem processual. Esta abordagem revela que o acesso ao conhecimento sobre as representações sociais parte do entendimento do ser humano como produtor de sentidos, focalizando-se na análise das produções simbólicas, dos significados e da linguagem, através dos quais o sujeito constrói o mundo em que vive ${ }^{(7)}$. Desta forma, a abordagem processual é a que mais se adequa ao objeto do presente estudo.

A pesquisa teve como campo de estudo um hospital público de referência nacional no tratamento do câncer, localizado na cidade do Rio de Janeiro. O número de sujeitos foi de 30 familiares de clientes oncológicos adultos que acompanharam o doente durante a consulta de enfermagem realizada antes de iniciar o tratamento quimioterápico ambulatorial.

Foram adotados os seguintes critérios de inclusão dos sujeitos: ter preferencialmente parentesco de primeiro grau com o paciente (pai, mãe, irmão, filho ou cônjuge) e ter acompanhando seu familiar por, pelo menos, uma das consultas de enfermagem: a de primeira vez ou a de retorno. Os critérios de exclusão usados foram: familiares com idade menor que 18 anos e não ter acompanhado o paciente em uma das consultas de enfermagem. Para garantir o anonimato, os sujeitos foram identificados pela letra $\mathrm{E}$ seguida de um número.

Após aprovação pelo Comitê de Ética em Pesquisa, foi iniciada a coleta de dados através de entrevistas semiestruturadas, que se orientam por um roteiro prévio e se caracterizam por sua reelaboração no processo de investigação, abrangendo questões e temáticas que não constavam em seu início ${ }^{(6)}$. As entrevistas foram gravadas em fitas magnéticas, transcritas na íntegra em arquivo Word e devolvidas aos sujeitos para confirmação de seus depoimentos. A partir de leitura em profundidade das en- trevistas e do material coletado, foi realizada a categorização temática.

Após a coleta de dados e a transcrição das fitas gravadas, passou-se à fase de exploração dos dados com o auxílio do software Qualitative Solutions Research Nvivo 2.0 (QRS Nvivo 2.0), que foi elaborado para a análise qualitativa de dados. Este software se fundamenta no princípio da codificação e armazenamento de textos em categorias específicas. Assim, a análise ocorreu a partir da definição prévia das dimensões representacionais classicamente consideradas pelos principais autores da teoria $^{(8,9)}$, como: sentimentos compartilhados por familiares de clientes oncológicos em tratamento quimioterápico; imagens, metáforas e conceitos do câncer para os familiares que enfrentam a doença; preconceitos e estigmas na vivência do câncer; as diferentes práticas de enfrentamento desenvolvidas no contexto da doença e do processo de adoecimento pelo câncer; o conhecimento acerca do câncer e alguns elementos de ancoragem; as vivências do enfermeiro que trabalha em oncologia e suas contribuições junto à família. Para efeito deste artigo, será aprofundada, especificamente, a dimensão relativa a diferentes práticas de enfrentamento desenvolvidas no contexto da doença e do processo de adoecimento pelo câncer.

\section{RESULTADOS E DISCUSSÃO}

Estima-se, para o Brasil, biênio 20182019, a ocorrência de 600 mil casos novos de câncer, para cada ano. Excetuando-se o câncer de pele não melanoma (cerca de 170 mil casos novos), ocorrerão $420 \mathrm{mil}$ casos novos de câncer. As doenças e agravos não transmissíveis (DANT) já são as principais responsáveis pelo adoecimento e óbito da população no mundo. Estima-se que, em 2008, 36 milhões dos óbitos (63\%) ocorreram em consequência das DANT, com destaque para as doenças cardiovasculares ( $48 \%$ das DANT) e o câncer - $21 \%{ }^{(10)}$.

As preocupações sobre como será a sua existência, após ter uma doença como o câncer, leva o doente e sua família a sen- tirem-se distantes da possibilidade de reordenar suas vidas. A perda do controle sobre a vida causa sofrimento e faz surgir sentimento de impotência, angústia e isolamento. Os familiares, na cotidianidade da doença e do tratamento, apresentam a necessidade de equilibrarem os seus próprios sentimentos, lidando com as questôes práticas da vida e, ainda, apoiando afetiva e psicologicamente a própria pessoa acometida pelo tumor. O sofrimento é então disfarçado, guardado, transformado em um acordo de silêncio tácito que, aparentemente, mantém as coisas nos seus devidos lugares, mas que imprime, ao dia a dia, uma configuração de 'bomba relógio' em que uma pequena alteração tende a dar vazão a todos os sentimentos guardados ${ }^{(1)}$.

Nesse contexto, pra enfrentar a doença e o adoecimento com mais significado e sentido, muitos pacientes passam a utilizar a espiritualidade como estratégia fundamental para conseguirem passar por todo esse processo, dando-lhes força para superar, coragem, alívio no sofrimento, o que contribui no processo de adesão e adaptação ao tratamento. Nesses momentos de ressignificação, a religiosidade e a espiritualidade podem atuar como um benefício para o paciente, contribuindo para a diminuição das experiências negativas provocadas pelo câncer e aprimorando sua qualidade de vida ${ }^{(11)}$.

O suporte espiritual é capaz de gerar esperança, reorganização e adaptação ao processo de adoecimento. Entende-se que a espiritualidade, ao ser comparada a uma âncora, pode significar, simbolicamente, algo para se "agarrar", se segurar, para não sucumbir e, assim, servir de estímulo/força propulsora necessária para o enfrentamento da doença ${ }^{(12)}$.

Apesar das diferentes crenças, os discursos nos mostram que, nos momentos mais difíceis do enfrentamento do câncer, as pessoas se voltam para a religião como forma de encontrar a esperança pela cura e, até mesmo, um pouco de conforto na fé.

"Tudo aquilo que você sabe que pode te levar à morte é ruim, mesmo sabendo, como hoje eu sou evangélico, $e$ 
para a gente que é evangélico tem que passar por aquilo, a gente acredita nisso, eu acredito que a minha esposa vai se curar, mas acreditar que o tratamento é $90 \%$ e $100 \%$ Deus, porque infelizmente a gente sabe que as pessoas fazem, o remédio que vem e o enfermeiro está ali para aplicar $o$ medicamento da melhor forma possível, para ela ter uma cura, mas não depende do enfermeiro, não depende do médico [...]" (E32).

A espiritualidade acaba por auxiliar no processo de ressignificação do câncer, causando uma motivação e aliviando possíveis medos ou crenças errôneas que possam surgir, já que o auxílio de uma força sobrenatural, ou não, se torna um importante aliado no combate ao sofrimento. Mas é importante ressaltar que a espiritualidade possa surgir após o impacto da doença, uma vez que estar mais próximo da presença da fé ameniza a sensação de estar mais próximo da morte ${ }^{(13)}$.

Fica evidente, nas falas dos sujeitos, a presença de uma força superior que os guia e os protege diante das situações adversas provenientes do câncer e de seu tratamento. Os problemas são colocados nas mãos do Divino para que ele possa atuar e operar de forma a solucionar o caso que, inicialmente, parecia não ter solução.

"O que eu pensei, porque graças a Deus, eu sou uma pessoa que tenho muita fé e confio muito em Deus, entendeu? Eu botei minha fé em Deus, confiando Nele, que ele ia operar, que ele ia se curar, que o problema estava muito sério, tava no reto, que o médico tinha dito que ele não ia poder tirar aquela bolsa, a colostomia, que é para separar pra sempre, confiando na fé que eu tenho e confiando em Jesus, graças a Deus, ele vai poder tirar com o tempo, depois da quimioterapia. Confio em Deus e em nome de Jesus ele vai ser curado mesmo, né?" (E19).

Quando se tem a sensação de que tudo está perdido, a busca pela religiosidade e pela fé torna-se elemento que impulsiona novo ânimo e esperança na vida das pessoas. Além disso, a possibilidade ou a crença de cura do indivíduo aparece na forma de um milagre prestes a acontecer. Observa-se que a fé e a confiança representam uma força propulsora que, aliada à crença em Deus, podem propiciar, às pessoas, a esperança da cura para a doença. A fé atua como elemento positivo no enfrentamento da doença e, nesse âmbito, é interpretada como uma estratégia utilizada para lidar com as incertezas da doença e superar as situações de crise vivenciadas ${ }^{(14)}$.

No enfrentamento do câncer, é possível observar que o suporte espiritual mobiliza mecanismos psicoemocionais capazes de amenizar a dor, o sofrimento, o medo e as incertezas. Estes mecanismos, além de fornecer o suporte necessário para a reflexão, possibilitam a reavaliação dos sentimentos, comportamentos e atitudes na forma de encarar a doença e o tratamento e, consequentemente, transformações e/ou adaptações no seu modo de viver ${ }^{(12)}$.

É pela via da espiritualidade que, muitas vezes, é possível encontrar possibilidades de intervenção que auxiliem no cuidado do paciente dentro do tratamento. A fé é capaz de reacender nas pessoas sentimentos como a esperança, algo fundamental dentro do quadro de hospitalização, uma vez que existe uma série de medos sobre o câncer construídos e reforçados socialmente ${ }^{(15)}$.

"Eu acho que a situação de ânimo do cidadão contribui e muito para que você tenha. Eu sou espirita. Dentro do espiritismo diz que quem tem câncer pode ser uma doença cármica, não é? Mas evidentemente que eu não vou ficar só com esse lado. Ou você pode ter nascido com alguma célula defeituosa, vamos chamar assim, se existe esse termo. Dentro desse conceito mais espiritual é dito que é uma doença cármica, mas eu não posso ficar somente nisso. O carma é uma coisa que você traz de outras vidas. Eu não sou uma profunda conbecedora do espiritismo, mas tive conversando também com gente que conhece, que é espírita, como se você trouxesse de outras vidas [...]" (E35).

A estratégia de enfrentamento de doença implica na participação de pessoas da família e na busca pela religiosidade. Ao se sentirem acometidos por alguma doença, as pessoas, de modo geral, ficam mais reflexivas e questionam suas próprias crenças religiosas e espirituais. A religião representa um importante apoio e suporte para o enfrentamento da doença. A fé proporciona conforto e segurança, sendo interpretada como uma estratégia para lidar com as incertezas ante a evolução da doença ${ }^{(16)}$.

$\mathrm{O}$ discurso a seguir nos mostra a importância da prática religiosa como instrumento que fortalece, incentiva e dá ânimo e esperança à vida dos familiares dos pacientes com câncer.

\section{"Eu confiei em Deus, mas mesmo as pessoas pensavam que meu espo- so ia morrer, porque ele tava mal mesmo, todo mundo, até os filhos dele pensavam, meus filhos pen- savam em passar mal, chegou pra mim e falou mãe só um milagre, só um milagre. Em nome de Jesus, você vai ver o milagre!" (E19).}

Conforme podemos observar na fala, os familiares dos pacientes com câncer indicam o quanto se sentem inseguros e vulneráveis diante do futuro. Entretanto, a fé é ressaltada por essas pessoas e evidencia que este sentimento as conforta e ameniza seu sofrimento. Depreende-se, então, que a fé representa poderosa força capaz de conduzir e impulsionar o enfrentamento da enfermidade alicerçadas na esperança da cura ou como atenuante do possível sofrimento iminente.

Assim, torna-se evidente a necessidade de o profissional de saúde estar atento à fé religiosa do paciente, bem como de seus familiares, reconhecendo a dimensão espiritual desses indivíduos na medida em que essa lhes traz estímulo, coragem e esperança de encarar a doença. A fé torna-se 


\section{artigo}

Souza, M.G.G.; Gomes, A.M.T.; Santo, F.H.E.; Andrade da Silva, L.; Marta, C.B.; Oliveira, L.A.F.; Mendonça, A.B.;

As práticas religiosas e os mecanismos de superação desenvolvidos por familiares de pacientes no enfrentamento do câncer

uma fonte de apoio para o enfrentamento do diagnóstico pelo paciente e seus familiares, bem como para conseguir suportar os desafios provocados pelos diversos tratamentos, ou até mesmo confortarem-se diante da impossibilidade de cura ${ }^{(4)}$.

"Ninguém quer ter na verdade, mas é uma coisa sem explicação, porque só Deus mesmo sabe aquilo que a gente tem que passar e o que não tem de passar, então acho que é um obstáculo que a gente tem que passar, vencer, mostrar a todos que é uma vitória" (E21).

É sabido que a religiosidade tem influência positiva no enfrentamento da doença, porém é necessário ampliar os estudos para aprofundar o tema em questão para que o paciente seja visto de forma holística. Diante disso, é importante a participação de pessoas das igrejas em hospitais ou locais em que os pacientes estão, para que possam realizar momentos em que possam expressar sua fé e viver a sua religiosidade.

\section{CONCLUSÃO}

Diante do exposto ao longe deste artigo, torna-se necessária a compreensão das imagens e dos conceitos do câncer para as famílias que possuem um ente querido nesta condição. Entender esta complexidade requer o envolvimento e o comprometimento dos profissionais que lidam com este tipo de público para uma melhora efetiva na qualidade de vida, tanto do doente, quanto de seus familiares. O cuidado ao outro deve envolver não apenas o aprimoramento de intervenções técnicas, mas muito mais que isso, envolve a atenção voltada para a individualidade e a estrutu- ra simbólica inserida em cada ser humano.

Contemplando o objetivo deste estudo, o conhecimento e valorização das práticas religiosas sob a óptica dos enfermeiros, a espiritualidade nas ações do cuidado ao paciente/usuário oncológico ainda é incipiente, pouco valorizada, com implicações na própria formação profissional evidenciadas pelo despreparo dos profissionais/ enfermeiros para lidar com os aspectos que integram a dimensão espiritual.

É imprescindível que os enfermeiros estejam atentos às necessidades e dimensões religiosas trazidas pelos pacientes e seus familiares, inclusive solicitando a colaboração de representantes religiosos, o que é essencial para o manejo clínico do paciente e de sua família, especialmente daqueles que se encontram em cuidados paliativos. Sugerem-se pesquisas que contemplem a temática com o intuito de instrumentalizar o profissional enfermeiro para sua prática.

\section{REFERÊNCIAS}

1. Souza MGG, Gomes AMT. Sentimentos compartilhados por familiares de pacientes oncológicos em tratamento quimioterápico: um estudo de representações sociais. Rev. enferm. UERJ. 2012 abr/jun; 20(2):149-54.

2. Antoniazzi AS, Dell'Aglio DD, Bandeira DR. O Conceito de coping: uma revisão teórica. Estudos de Psicologia. 1998; 3(2):273294.

3. Thuné-Boyle ICV, Stygall LJ, Keshtgar MRS, Davison TI, Newman SP. Religious coping strategies in patients diagnosed with breast cancer in the UK. Psycho-Oncology. 2011; 20(7):771-782.

4. Murakami R, Campos CJG. Religião e saúde mental: desafio de integrar a religiosidade ao cuidado com o paciente. Revista Brasileira de Enfermagem. 2012; 65(2):361-7.

5. Triviños ANS. Introdução à pesquisa em ciências sociais. São Paulo: Atlas; 2009.

6. Minayo MCS, organizador. Pesquisa social: teoria, método e criatividade. 6. ed. Petrópolis: Vozes; 1996.

7. Banchs MA. Alternativas de apropiación teórica: abordage processual y estructural de lãs representaciones socials. Educ cult Contemp. 2004; 1(2):39-60.

8. Moscovici S. Representações sociais: investigações em psicologia social. 6. ed. Petrópolis: Vozes; 2009.

9. Sá CP. Representações sociais: o conceito e o estado atual da teoria. In: Spink MJ. O conhecimento no cotidiano. São Paulo:
Brasiliense; 1993.

10. Santos DL, Barreto DCOV, Silva LA, Marques LR, Machado PRF, Marta CB. Contributos que afetam a saúde mental do enfermeiro: revisão integrativa. Saúde Coletiva (Barueri). 2019 abr/ mai/jun; 48:1291-1295.

11. Gobatto CA, Araujo TCCF. Religiosidade e espiritualidade em oncologia: concepções de profissionais da saúde. Psicol. USP. 2013; 24(1):11-34.

12. Siqueira HCH, Cecagno D, Medeiros AC. Espiritualidade no processo saúde-doença-cuidado do usuário oncológico: olhar do enfermeiro. Rev enferm UFPE on-line. 2017 ago; 11(8):29963004.

13. Cardoso AHA. Espiritualidade e câncer em pacientes submetidos a tratamento quimioterápico. 2014. 35 p. Monografia (Graduação em Enfermagem) - Universidade Estadual da Paraíba, Campina Grande. 2014.

14. Benites AC, Neme CMB, Santos MA. Significados da espiritualidade para pacientes com câncer em cuidados paliativos. Estudos de Psicologia. 2017;34(2):269-79.

15. Sousa FFDPR, Freitas SMFM, Farias AGS, Oliveira MDCS, Araújo MFM, Veras VS. Enfrentamento religioso/espiritual em pessoas com câncer em quimioterapia: revisão integrativa da literatura. SMAD-Revista Eletrônica Saúde Mental Álcool e Drogas. 2017; 13(1):45-51.

16. Pinto $A C$, et al. A Importância da espiritualidade em pacientes com câncer. Rev. Saúde.Com. 2015; 11(2):114-122. 